\title{
CHAUCER, Geoffrey. Contos da Cantuária. Tradução do inglês moderno e notas de José Francisco Botelho. São Paulo: Penguin Classics Companhia das Letras, 2013. 680 p.
}

\section{Uma nova tradução}

O aparecimento da tradução de uma obra como The Canterbury Tales deve ser saudado como um acontecimento editorial em qualquer língua, tanto pela importância desse texto para a literatura universal quanto pela grandeza da tarefa de vertê-lo para outro idioma. $\mathrm{Na}$ língua portuguesa, uma nova edição reveste-se de relevância ainda maior, uma vez que não possuíamos até agora uma tradução completa de tal obra em versos. As tentativas anteriores apresentavam características formais mistas ou fragmentárias.

Escrita na segunda metade do século XIV, The Canterbury Tales reflete as vicissitudes de uma época cheia de eventos como foi a da vida de seu autor, Geoffrey Chaucer (1343-1400). Filho da burguesia ascendente, que tinha acesso à instrução e tomava sobre si a responsabilidade de produzir uma cultura laica, em substituição à cultura essencialmente religiosa proveniente dos mosteiros, Chaucer aproximou-se da corte, servindo a sucessivos reis como funcionário público justamente quando a Inglaterra vivia o início dos conflitos da Guerra dos Cem Anos com a França e várias irrupções da Peste Negra assolavam a Europa. Aprendeu idiomas e viajou a serviço, conhecendo vários países (França, Itália) e suas manifestações culturais. Acredita-se que o conhecimento do Decameron, de Giovanni Boccaccio, para citar apenas um nome, foi determinante para a produção dos Canterbury Tales. Por outro lado, a obra de Chaucer também se beneficia do contato com uma longa série de relatos encontrados na literatura desde a antiguidade (cf. CARTER, McRAE, 2001; SANDERS, 1996).

A novidade e a contribuição permanente dos Canterbury Tales encontra-se menos na invenção pura de histórias originais (poucas) do que na imitação criativa de histórias conhecidas, a que Chaucer empresta uma graça e vivacidade especial. Tais qualidades devemse, principalmente, à moldura que o narrador principal cria para que as trinta personagens (uma das quais, ele mesmo), por sua vez, contem suas histórias. Como se sabe, as personagens encontram-se numa taberna em Southwark, nas imediações de Londres, na véspera de sua partida para Cantuária, local de peregrinação desde que lá fora assassinado o Bispo Thomas Becket. Conforme sugestão do taberneiro, a fim de evitar o aborrecimento da longa viagem a cavalo, cada um dos peregrinos deverá contar duas histórias na ida e duas na volta de Cantuária, recebendo o melhor contador um jantar pago por todos os outros ao final da peregrinação. O grupo, apresentado no "Prólogo", inclui pessoas de diversos níveis sociais e profissões, o que confere colorido, coesão e representatividade à composição. Mas uma vida não foi suficiente para compor todas as 120 histórias planejadas. Ao morrer, o autor nos legou um conjunto de 24 narrativas, sendo que algumas dessas incompletas.

Escritos em médio inglês, ou, segundo alguns, numa linguagem que já pode ser considerada moderna, nas universidades dos países anglófonos, ou nas universidades estrangeiras que possuem cursos de Anglística, os Canterbury Tales são lidos diretamente no original. Para isso, o estudante dedica-se, por alguns semestres, à aquisição dessa forma da língua, que difere significativamente do inglês antigo, em que estão escritos poemas como Beowulf (provavelmente do século VI d.C.), ou do inglês moderno, cuja fase inicial é tradicionalmente atribuída aos textos de Shakespeare. Ora, sabe-se quantas dificuldades os textos dos séculos XVI ao XVIII, para não incluir também o XIX, costumam provocar ao estudante, para não falar do leitor sem especialização A este, seja ele nativo ou estrangeiro, destinam-se as traduções intralinguais - no presente caso, a tradução de Chaucer para o inglês moderno.

É preciso admitir também que, apesar de o ensino de inglês em toda parte haver se tornado, depois da Segunda Guerra Mundial, um fenômeno ímpar na história da humanidade, ainda existe, nos vários países, um número significativo de pessoas que não falam nem leem esse idioma. Além disso, existe o fato, ainda mais relevante, de que uma cultura encontra-se incompleta quando está isolada, e que um dos meios mais eficazes de completar-se 
- na realidade, uma tarefa incessante - é a importação de elementos de outras culturas. Tal processo se dá através da tradução.

No Brasil, Paulo Vizioli (1934-1999), professor da Universidade de São Paulo, lançou em 1988 (reimpressa em 1991) uma tradução completa dos Canterbury Tales (CHAUCER, 1988). A língua portuguesa só possuía, até então, a tradução parcial de Olívio Caeiro, constituída do "Prólogo" e de dois contos (CHAUCER, 1980). O Prof. Vizioli tomou como texto de partida para sua tradução as edições em inglês médio dos eruditos W. W. Skeat e F. N. Robinson, enriquecendo-as com uma substanciosa apresentação, 289 notas de fim e boa bibliografia. Entendendo as narrativas de Chaucer essencialmente como contos, que seguem a tradição medieval de empregar o verso metrificado e rimado em vários tipos de textos, literários ou não, o tradutor optou por traduzi-las para o português em prosa. Exceções de trechos metrificados encontram-se no "Conto do magistrado" (CHAUCER, 1988:71s), no "Conto da prioresa" (Idem, 96s), no "Conto de Chaucer sobre Sir Topázio" (Idem, 101-106), no "Conto do estudante" (Idem, 191s) e no "Conto da outra freira" (Idem, 253s). O tradutor justifica essa escolha formal com a tentativa de "preservar a natureza e a qualidade das imagens do autor, as nuanças das diferentes atmosferas, a sutileza e a variedade dos tons, e, inclusive, a musicalidade das palavras" (Idem, XXIII). Nesse aspecto, aliás, como em tudo, seus critérios são respeitáveis e os resultados, altamente satisfatórios. Essa tradução teve recentemente uma edição bilíngue acrescida de notas e um posfácio de José Roberto O'Shea (CHAUCER, 2014).

Paulo Vizioli possuía qualidades que o habilitavam também para uma tradução em versos, o que fica sobejamente provado em outra obra, a bilíngue $A$ literatura inglesa medieval (VIZIOLI, 1992). O poeta, critico, professor e tradutor, após verter excertos comentados de Beowulf e outros textos em antigo e médio inglês, torna aos Canterbury Tales. São magníficas suas traduções de excertos do "Prólogo" e do "Conto do padre da freira" (Idem, 93-131). Em decassílabos heroicos, poucos versos fogem, quanto à acentuação e às rimas emparelhadas, do esquema métrico, rítmico e sonoro do original.

A tradução de José Francisco Botelho (CHAUCER, 2013), exceção feita de alguns trechos que se costumam apresentar em prosa - o "Conto de Chaucer sobre Melibeu", o "Conto do pároco" e a "Retratação de Chaucer" -, inteiramente em versos, emula não só as traduções de Paulo Vizioli, mas todas as traduções dos Canterbury Tales "in existence" na língua portuguesa. Dedicaremos as próximas páginas ao exame das características internas e externas dessa tradução, ou seja, como se apresenta nela a obra de Chaucer e o que sobre ela se diz.
Quanto à opção por um texto de partida, José Francisco Botelho optou pela tradução para o inglês moderno, com introdução e notas, de Nevill Coghill. Valeu-se, além disso, do cotejo com o original em inglês médio de W. W. Skeat. Seguindo o texto de Coghill, o tradutor opta também por uma distribuição dos contos, que difere, aqui e ali, da ordem estabelecida por Skeat. A alteração da ordem fica especialmente notável na antecipação do "Conto do vendedor de indulgências" ao "Conto da mulher de Bath", que, junto com o "Conto do cavaleiro" (o primeiro da série) e o "Conto do padre da freira", estão entre as histórias mais conhecidas e apreciadas dos Canterbury Tales. Tais divergências na ordem de apresentação refletem as diferenças de compreensão entre os estudiosos da obra de Chaucer e devem-se, entre outros fatores, ao caráter fragmentário do texto. $\mathrm{O}$ favorecimento de uma ou outra sequência baseia-se, principalmente, no comentário dos próprios peregrinos aos contos de seus companheiros, bem como nas exortações, ordens e críticas distribuídas fartamente pelo mestre de cerimônias, o taberneiro. Mas cada conto vale também por si, apresentando-se como uma amostra dos vários tipos de narrativa correntes no mundo medieval: a lenda, a fábula, o exemplo, e assim por diante. Em muitos deles é possível reconhecer também uma contribuição "autobiográfica" do narrador, frequentemente expresso na introdução e conclusão particulares que adita ao conto. Exemplos bem evidentes de tal recurso encontram-se nos relatos do vendedor de indulgências e da mulher de Bath. Não fossem eles personagens, figuras ficcionais, acreditaríamos estar diante de discursos (precoces na história da literatura) que misturam a defesa da própria causa ao auto-elogio e à confissão desassombrada dos próprios defeitos.

Outras decisões que se encontram no texto de Coghill e que coube ao tradutor seguir referem-se às sinopses de trechos considerados prolixos ou de pouco interesse para o leitor. É o caso do já mencionado "Conto de Chaucer sobre Melibeu". As mil linhas do original desse trecho em prosa resultariam em mais cerca de 30 páginas de tradução. Mas é certamente o fato de tratar-se de uma "homilia dialética ou um debate moral" (CHAUCER, 2013:235), e portanto pouco palatável ao leitor moderno, que pesou na decisão de resumir esse trecho. Razão semelhante se poderia aduzir para o "Conto do pároco": "um sermão, em prosa, sobre as devidas preparações para a confissão e a verdadeira natureza dos sete pecados capitais" (CHAUCER, 2013, p. 599). Também essa passagem, que já rendeu um interessante filme, é apresentada em sinopse.

Mas nenhuma dessas e das tantas outras características do texto de Chaucer ficaria evidente ao leitor se não tivessem sido postas em evidência pela tradução 
de José Francisco Botelho. Brinda-nos ele com uma tradução integral em decassílabos rimados. Para um texto de grande fôlego como os Canterbury Tales, a simples tentativa de fazê-lo, independentemente das qualidades do resultado, já merece ser enaltecida como um ousado empreendimento. O tradutor levou-o a cabo com proficiência e capacidade. De fato, no longo texto, o leitor comum encontra uma rendição fidedigna de uma das obras centrais da literatura inglesa, e o observador da tradução, além disso, uma demonstração de recursos de toda ordem - temáticos, narrativos, poéticos, humorísticos, lexicais, para mencionar apenas alguns - que compõem uma grande obra literária. Seria difícil, nas quase 600 páginas que compõem essa tradução, encontrar os trechos mais bem realizados. Sirva de exemplo a abertura do "Prólogo geral":

\footnotetext{
Quando o chuvoso abril em doce aragem

Desfez março e a secura da estiagem,

Banhando toda a terra no licor

Que encorpa o caule e redesperta a flor,

E Zéfiro, num sopro adocicado,

Reverdeceu os montes, bosques, prados,

E o jovem sol, em seu trajeto antigo,

Já passou do Carneiro do Zodíaco,

E melodiam pássaros despertos,

Que à noite dormem de olhos bem abertos,

Conforme a Natureza determina

- É que o tempo chegou das romarias.

E lá se vão expertos palmeirins

Rumo a terras e altares e confins;

Da vária terra inglesa, gente vária

Põe-se a peregrinar a Cantuária

Onde jaz a sagrada sepultura

Do mártir que lhes deu auxílio e cura.

(CHAUCER, 2013, p. 23)
}

Chama a atenção a fluência desses versos, a regularidade das rimas emparelhadas e o ritmo, com acento, raramente violado, na sexta e décima sílabas. Inúmeras passagens desse quilate podem ser encontradas, sendo de recomendar-se, quanto à fluência, o nunca suficientemente elogiado "Conto do cavaleiro", que se segue imediatamente ao "Prólogo geral". O motivo dessa nobre história de amor e amizade, o elevado estilo e a fluidez dos versos nunca serão suficientemente recomendados. Opõem-se a ela outras de tom burlesco e vulgar, em que predomina o elemento humorístico, como o "Conto do moleiro" e o "Conto do feitor", todas elas bem traduzidas. Embora de tom leve, são de maior complexidade retórica do que esses últimos o "Conto do padre da freira", o "Conto da mulher de Bath" e o "Conto do vendedor de indulgências". Encontram-se eles entre os mais antológicos e elogiados contos de Chaucer, e a tradução de José Francisco Botelho lhes faz plena justiça.
Pautando-se pela fidelidade, o tradutor não deixa de ser inventivo em suas soluções para as passagens difíceis, que são inúmeras em obra de tamanha variedade e magnitude. Tem curso atualmente entre os teóricos o ideal da manutenção de certo "estranhamento cultural" - de que o tradutor está consciente (CHAUCER, 2013, p. 17) -, e que se opõe a uma tradução domesticadora, em que quase tudo é adaptado ao ambiente de chegada ${ }^{1}$. Não podemos dizer se tal foi a intenção ao manter no masculino o nome da Morte ("Dom Morte", no "Conto do vendedor de indulgências"). Nesse caso, o masculino é de uso corrente na língua inglesa em situação em que na língua portuguesa se emprega sempre o feminino. Comparando, verificamos que Paulo Vizioli preferiu o emprego consagrado em português.

Não nos referiremos aqui a certas rimas que os parnasianos chamariam de "imperfeitas", ou a pequenas quebras de ritmo, quando a acentuação se desvia da sexta e décima sílabas: o fato é que as semelhanças sonoras são alcançadas com engenhosidade, e que o fluxo da leitura raramente é interrompido. Um aspecto de outra ordem que merece atenção, no entanto, aparece no título, Contos da Cantuária. Não sabemos se a contração da preposição com o artigo ocorreu no processo de edição, mas poucos nomes de cidades, na língua portuguesa são precedidos de artigos, sempre masculinos: o Rio de Janeiro, o Recife (em desuso, na fala corrente), o Porto, o Cairo e o Havre. Acrescentam-se nomes com o artigo feminino, quando o nome da cidade vem precedido com "a cidade do", como "a Cidade do Cabo", "a Cidade do México". Apesar da restrição, encontram-se, com frequência, em nível jornalístico, artigos diante de topônimos como Filadélfia, Basileia e Antuérpia. Foi o que aconteceu, no presente caso com Cantuária, nome da capital do condado de Kent, na Inglaterra. Não faltaram exemplos anteriores do emprego sem artigo: as traduções de Paulo Vizioli e Olívio Caeiro omitem-no, tal qual o texto original da tradução do ensaio de Harold Bloom que compõe o paratexto da presente edição - alterado para fazer parte do presente livro. Na realidade, várias passagens mostram que houve hesitação no emprego dessa estrutura, e que o artigo parece ter sido introduzido "a posteriori" para fins de uniformização. Mesmo um exemplo de emprego com artigo encontrado na internet, em português de Portugal, não justificaria a extensão do uso para o Brasil. É, no entanto, como já dissemos, um grão de areia que, a ser considerado um defeito, não obscurece os méritos de obra tão vasta e variada.

Por fim, uma palavra sobre o já mencionado paratexto editorial. Seguem o padrão da editora Penguin a capa e as informações a respeito do autor, dos tradutores

\footnotetext{
Ver, a esse respeito, Venuti, 1995.
} 
inglês (falecido em 1980) e brasileiro, bem como de Harold Bloom. A introdução de Nevill Coghill é de grande utilidade, tanto para o leitor experiente como para aquele que se defronta pela primeira vez com um texto traduzido do inglês medieval. $\mathrm{O}$ tradutor brasileiro, por sua vez, acrescentou uma "Nota sobre a tradução", em que apresenta as bases de seu trabalho, que vão desde a identificação do texto de partida e das principais fontes consultadas à apresentação dos critérios que nortearam a escolha das formas adotadas na tradução metrificada dos versos de Chaucer. Pode-se dizer que o tradutor está bem consciente da complexidade de sua missão de trazer Chaucer para o leitor contemporâneo de língua portuguesa sem concessões nem simplificações. Às notas finais de Coghill acrescentou o tradutor brasileiro as suas próprias, baseadas na consulta acurada às fontes e ao estudo paciente dos textos medievais. Por fim, agregouse a essa edição dos Cantos de Cantuária o ensaio "Chaucer: a esposa de Bath, o vendedor de indulgências e a personagem shakespeariana" de Harold Bloom. Nesse texto, originalmente um dos capítulos de $O$ cânone ocidental, Bloom associa as personagens chaucerianas mencionadas no título às personagens Falstaff (a mulher) e Iago e Edmundo (o vendedor), situando-as assim no largo esquema que constitui a sua visão personalizada da literatura e cujo centro é Shakespeare.

Ao tradutor dos Cantos de Cantuária podemos prestar homenagem relendo esse riquíssimo texto em nosso idioma e expressando nossos votos de que muitas outras obras-primas ainda sejam por ele vertidas para a língua portuguesa.

\section{Referências}

BLOOM, Harold. O cânone ocidental: os livros e a escola do tempo. Tradução de Marcos Santarrita. Rio de Janeiro: Objetiva, 1995. p. 107-127.

CARTER, Ronald; McRAE, John. The Routledge History of Literature in English. London: Routledge, 2001.

CHAUCER, Geoffrey. Contos da Cantuária. Tradução do inglês moderno e notas de José Francisco Botelho. São Paulo: Penguin Classics Companhia das Letras, 2013.

CHAUCER, Geoffrey. Os contos de Cantuária. Apresentação e tradução direta do Médio Inglês e notas de Paulo Vizioli. São Paulo: T. A. Queiroz, 1988.

CHAUCER, Geoffrey. Os contos de Canterbury: texto bilíngue. Apresentação e tradução direta do Médio Inglês e notas de Paulo Vizioli, posfácio e notas adicionais de José Roberto O’Shea. São Paulo: Editora 34, 2014.

CHAUCER, Geoffrey. Os contos de Cantuária. Seleção, prólogo e dois contos traduzidos por Olívio Caeiro. Lisboa: Brasília Editora, 1980.

CHAUCER, Geoffrey. The Canterbury Tales. Translated into Modern English by Nevill Coghill. London: Penguin Classics, 2003.

SANDERS, Andrew. The Short Oxford History of English Literature. Revised ed. Oxford: OUP, 1996.

VENUTI, Lawrence. The Translator's Invisibility: A History of Translation. London and New York: Routledge, 1995.

VIZIOLI, Paulo. A literatura inglesa medieval. Introdução, seleção, tradução e notas de Paulo Vizioli. São Paulo: Nova Alexandria, 1992. p. 7-27; 93-131.
PEDRO THEOBALD

Pontifícia Universidade Católica do Rio Grande do Sul
Recebido: 15 de outubro de 2015 Aprovado: 18 de dezembro de 2015 Contato: perth@pucrs.br 